\title{
Environmental Factors Affecting Production, Release, and Field Populations of Conidia of Alternaria alternata, the Cause of Brown Spot of Citrus
}

\author{
L. W. Timmer, Z. Solel, T. R. Gottwald, A. M. Ibañez, and S. E. Zitko
}

First, fourth, and fifth authors: University of Florida, Citrus Research and Education Center, Lake Alfred 33850; second author: Department of Plant Pathology, Agriculture Research Organization, The Volcani Centre, Bet Dagan 50250, Israel; and third author: U.S. Department of Agriculture, Agricultural Research Service, Horticultural Research Laboratory, Orlando, FL 32803.

Accepted for publication 3 August 1998.

\section{ABSTRACT}

Timmer, L. W., Solel, Z., Gottwald, T. R., Ibañez, A. M., and Zitko, S. E. 1998. Environmental factors affecting production, release, and field populations of conidia of Alternaria alternata, the cause of brown spot of citrus. Phytopathology 88:1218-1223.

Alternaria brown spot, caused by Alternaria alternata pv. citri, affects many tangerines and their hybrids, causing loss of immature leaves and fruit and reducing the marketability of the remaining fruit. Conidial production of A. alternata was greatest on mature leaves moistened and maintained at near $100 \%$ relative humidity $(\mathrm{RH})$ for $24 \mathrm{~h}$, whereas leaves that had been soaked or maintained at moderate RH produced few conidia. Conidial release from filter paper cultures and infected leaves was studied in a computer-controlled environmental chamber. Release of large numbers

Alternaria brown spot is a serious disease of certain tangerine and tangerine hybrids and causes abscission of immature fruit and leaves and blemishes on more mature fruit. The disease was first recorded in Australia on Emperor mandarin in 1903 (5,9), later appeared in Florida (United States) $(16,17)$ and Israel $(13)$, and now occurs in South Africa (12), Turkey (1), Colombia (2), and probably other areas where susceptible cultivars are grown. The causal agent was originally designated as Alternaria citri Ellis \& N. Pierce in N. Pierce and later termed A. alternata (Fr.:Fr.) Keissler, but the proper specific classification of the causal organism remains in doubt (18). At least two genetically distinct strains of the citrus pathogen exist, one affects tangerines and the other attacks rough lemon and Rangpur lime. Each strain produces a well-characterized, host-specific toxin with different modes of action (6).

Little is known about production or release of conidia of Alternaria on citrus. On other hosts, conidia of Alternaria spp. are usually produced on infected tissues and dispersed passively, primarily by strong, turbulent winds (11). However, there are indications that conidia of some Alternaria spp. may be actively released from conidiophores. Meredith (8) found that conidia of A. tenuis on banana were released during a shift from wetness to dryness. Air bubbles formed on the conidial chains during drying and caused twisting of the chains and release of conidia. Leach (7) also found that conidia of $A$. tenuis were released following both increases and decreases in relative humidity $(\mathrm{RH})$ as well as exposure to red/infrared (R/IR) irradiation. With A. solani, Gottwald et al. (4) found that abrupt increases or decreases in $\mathrm{RH}$, vibration, or brief rain events all stimulated conidial release, but exposure to R/IR irradiation did not.

Corresponding author: L. W. Timmer; E-mail address: 1wt@icon.lal.ufl.edu

Publication no. P-1998-0915-01R

(C) 1998 The American Phytopathological Society of conidia was triggered from both substrates by sudden drops in RH or by simulated rainfall events. Vibration induced release of low numbers of conidia, but red/infrared irradiation had no effect. In field studies from 1994 to 1996, air sampling with a 7-day recording volumetric spore trap indicated that conidia were present throughout the year with periodic large peaks. The number of conidia captured was not closely related to rainfall amounts or average wind speed, but was weakly related to the duration of leaf wetness. Likewise, disease severity on trap plants placed in the field weekly during 1995 to 1996 was not closely related to conidial numbers or rainfall amounts, but was weakly related to leaf wetness duration. Sufficient inoculum appears to be available to allow infection to occur throughout the year whenever susceptible host tissue and moisture are available.
The effect of environmental factors on populations of conidia in the field and on infection of citrus tissues by Alternaria has not been investigated. Extensive studies have been done on Alternaria spp. on other crops and have been reviewed elsewhere $(11,15)$. Alternaria spp. are environmentally flexible pathogens, and the same species may thrive under high rainfall conditions as well as in relatively arid areas (11). On citrus, Alternaria brown spot is a serious disease in high rainfall areas such as Florida and Colombia $(2,16,17)$ as well as in Mediterranean climates where virtually no rain falls after petal fall $(1,13)$. Conidia tolerate extremes in weather conditions and can survive extended unfavorable periods. Generally, Alternaria spp. reproduce rapidly at high temperatures, but moisture in the form of dew or rainfall seems to be necessary for infection in most cases (11).

The purpose of the current study was to determine the effect of moisture conditions on the production of conidia and the effect of changes in RH, R/IR irradiation, rainfall events, and vibration of the substrate on release of conidia of the tangerine strain of A. alternata on citrus. The seasonal patterns of conidial production under field conditions and the relationship of environmental conditions to production of conidia and to infection of young leaves were investigated. Portions of this work were published previously in a brief report (14).

\section{MATERIALS AND METHODS}

Moisture conditions for sporulation on infected leaves. Leaves of Minneola tangelo (Citrus reticulata Blanco $\times$ C . paradisi Macfad.) with lesions of Alternaria brown spot were collected from a grove near Polk City, FL. Infected leaves that had matured recently were selected from the tree canopy. Leaf pieces about 3 to $4 \mathrm{~cm}^{2}$ and bearing a single lesion about 0.5 to $1.0 \mathrm{~cm}$ in diameter were cut from the leaves. Ten leaf pieces with lesions were clamped between two $10 \times 15-\mathrm{cm}$ rectangles of wire mesh with a mesh size of $0.5 \mathrm{~cm}$. Treatments were designed to simulate moisture conditions that might occur on leaves with lesions within the tree can- 
opy or on the orchard floor. Treatments were (i) leaf pieces soaked $2 \mathrm{~h}$ in tap water and then placed on a wire support in a plastic humid chamber maintained at near $100 \% \mathrm{RH}$ for $22 \mathrm{~h}$; (ii) leaf pieces dipped briefly in tap water and then placed in a humid chamber as above for $24 \mathrm{~h}$; (iii) leaf pieces placed directly in the humid chamber as above without wetting; and (iv) leaf pieces held under ambient conditions in the laboratory (50 to $70 \% \mathrm{RH}$ ) for $24 \mathrm{~h}$. Three replicate grids with 10 lesions each were used for each treatment. After incubation at room temperature $\left(21\right.$ to $\left.24^{\circ} \mathrm{C}\right)$ in the laboratory, lesions were examined with a dissecting microscope and scored as positive or negative for mycelial growth and conidiophore production. The number of conidiophore groups bearing conidia on each lesion was counted. Each group was usually composed of three to eight conidiophores that emerged from the same point on the leaf. The experiment was conducted twice, and results of both experiments are presented. Data were subjected to analysis of variance, and means were separated using the Waller-Duncan $k$-ratio $t$ test.

Conidial release. A computer-controlled environmental chamber (CCEC) (4) was used to determine the environmental factors affecting conidial release. Using the CCEC, the effects of changes in $\mathrm{RH}$, rainfall events, R/IR irradiation, and vibration on conidial release were examined. All methods pertaining to the chamber design and application of these treatments are presented in Gottwald et al. (4). The experiments conducted and the factors evaluated in each are presented in Table 1.

Conidia for six experiments were produced in vitro on filter paper (experiments AA1 to AA6). Three hundred grams of immature leaves of Minneola tangelo was cut into $1-$ to $2-\mathrm{cm}^{2}$ pieces and boiled in 1 liter of water for $15 \mathrm{~min}$. The leaf decoction was filtered through cheesecloth and autoclaved. Sterile $3 \times 3-\mathrm{cm}$ filter papers were dipped in the leaf decoction and placed in a sterile petri dish. Cultures of A. alternata were grown on potato dextrose agar for 4 days at $27^{\circ} \mathrm{C}$. Aerial mycelium was scraped from the colony and suspended in $1 \mathrm{ml}$ of sterile distilled water and the resulting suspension used to seed the filter papers. After 1 to 2 weeks at $27^{\circ} \mathrm{C}$, conidiophores covered the entire surface of the filter paper and bore abundant conidia. Two $3 \times 3-\mathrm{cm}$ filter paper squares were placed in the CCEC specimen holder and then inserted directly into the chamber of the CCEC for conidial release studies.

Another four experiments were conducted with conidia produced on leaf lesions (experiments AA7 to AA10). Leaf pieces with lesions were placed in a wire grid as in the sporulation studies above, moistened, and maintained in the humid chamber for $24 \mathrm{~h}$. In lieu of the specimen holder, wire grids supporting leaf tissue with about 40 to 50 sporulating lesions were placed directly in the CCEC.

To evaluate the effects of the treatments to induce conidia release, the total number of conidia captured during a 10-min period during and immediately following treatment was compared with a similar period without the treatment using $t$ tests. For abrupt changes in $\mathrm{RH}$ from 90 to $15 \%$, the three cycles in experiment AA1 and the five cycles in experiment AA2 (Table 1) were compared with release at a constant $90 \%$ RH. For rain effects, six events were examined, one in experiment AA7, two in AA8, and three in AA10. The effect of R/IR irradiation was studied during one exposure in experiment AA7, three in AA8, and two in AA9. The effect of vibration was evaluated during three events in experiment AA4, one in AA7, and three in AA8. Other manipulation of environmental factors and combinations thereof were also evaluated as shown in Figures 1 to 4.

Field studies. Airborne conidia were trapped continuously from March 1994 to February 1996 in a Minneola tangelo grove severely affected by Alternaria brown spot near Polk City. A 7-day recording volumetric spore trap constructed by the authors was used. The trap was a modification of that of Gadoury and MacHardy (3), designed to be more sturdy and durable for year-long use in citrus orchards. In principle, it functions in the same manner as the Gadoury-MacHardy trap and the Burkard volumetric spore sampler (Burkard Scientific Sales Ltd., Rickmansworth, Hertfordshire,
United Kingdom). The spore trap tapes were coated first with a base layer consisting of gelvitol (35 g), glycerol $(50 \mathrm{ml})$, phenol $(2 \mathrm{~g})$, and distilled water $(100 \mathrm{ml})$, followed by a second adhesive coating consisting of petroleum gel (25 g), paraffin wax (12 g), and toluene (about $50 \mathrm{ml}$, the amount was varied according to temperature in the field, i.e., less used in the summer). The 7-day tapes were removed from the drum, cut into 1-day segments, mounted on microscope slides, and stained with cotton blue-lactophenol. Conidia were counted in a single pass across each 1-day segment at $\times 400$ magnification, and data collected were the total number observed per day or per week. Temperature, leaf wetness, wind speed, and rainfall data were collected at the site using a Campbell 21X micrologger (Campbell Scientific, Inc., Logan, UT). The micrologger was placed within the tree row in a location with a missing tree. The wind speed and temperature sensor and the rainfall gauge were located in the open area between trees. The leaf wetness sensor was placed on the north side of a tree on the edge of the canopy at about mid-canopy height. Data collected were daily and weekly average temperatures, proportion of hours with greater than $10 \%$ leaf wetness, average wind speeds, and total rainfall.

Seedlings of Dancy tangerine ( $C$. reticulata), which are highly susceptible to Alternaria brown spot, were used as trap plants to determine the disease severity occurring during each week of 1995 to 1996. Eight greenhouse-grown seedlings in 2.5-liter pots, pruned so that they had 30 immature, susceptible leaves each, were placed in the grove for 7 days. Four trap plants were placed in a group at the tree dripline, and the other four were placed in an adjacent row near the spore trap and micrologger. Trap plants were returned to the greenhouse, incubated an additional 5 days to allow symptom development under dry conditions, and the number of leaves with Alternaria lesions on each plant was counted.

Regression analysis was used to relate daily and weekly numbers of conidia trapped to rainfall amounts, proportion of hours with leaf wetness, and average daily wind speed. The same analyses were conducted with the original conidial numbers as well as with log-transformed data. Regression analyses were also used to relate weekly disease severity ratings to weekly rainfall totals, proportion of hours with leaf wetness, and weekly conidia totals. The number of conidia on days with and without rain were compared using $t$ tests.

Cultures of Alternaria were collected in the experimental grove by exposing plates of a selective medium to air to determine the percentage of conidia captured by the spore trap, which represented isolates pathogenic to citrus. The selective medium of Pryor et al. (10) was used; however, benomyl at $100 \mu \mathrm{g} / \mathrm{ml}$ was substituted for triadimefon and thiabendazole. On 29 May, 19 June, and 26 June 1996, 30 plates were exposed for $1 \mathrm{~h}$ in various locations near the spore trap, sealed, returned to the laboratory, and incubated for $27^{\circ} \mathrm{C}$ for 1 week. Conidia produced on each Alternaria colony on the selective medium were collected with a dissecting needle and

TABLE 1. The factors ${ }^{\mathrm{y}}$ evaluated in each experiment on conidial release conducted in the computer-controlled environmental chamber

\begin{tabular}{|c|c|}
\hline Experiment no. ${ }^{\mathrm{z}}$ & Environmental factor (no. of times evaluated) \\
\hline \multicolumn{2}{|l|}{ Filter paper } \\
\hline AA1 & $90 \rightarrow 15 \%$ RH (3); R/IR (3) \\
\hline AA2 & $90 \rightarrow 15 \%$ RH (5); R/IR (1) \\
\hline AA3 & $90 \rightarrow 70 \rightarrow 50 \rightarrow 30 \rightarrow 15 \% \mathrm{RH}$ \\
\hline AA4 & $90 \rightarrow 70 \rightarrow 50 \rightarrow 30 \rightarrow 15 \%$ RH (6); vibration (6) \\
\hline AA5 & $90 \rightarrow 15 \%$ RH (1); rain (1) \\
\hline AA6 & $90 \rightarrow 15 \%$ RH (1); rain (1) \\
\hline \multicolumn{2}{|l|}{ Leaf surface } \\
\hline AA7 & $90 \rightarrow 50 \%$ RH (1); R/IR (1); vibration (2); rain (1) \\
\hline AA8 & Vibration (3); R/IR (3); $50 \rightarrow 15 \%$ RH (2); rain (2) \\
\hline AA9 & $\mathrm{R} / \mathrm{IR}(2)$; rain $(1)$ \\
\hline AA10 & Repeated sequential rain events \\
\hline
\end{tabular}

$\mathrm{y}$ The factors: change in relative humidity $(\mathrm{RH})$, red/infrared (R/IR) irradiation, rain events, and vibration to simulate wind movement.

${ }^{\mathrm{z}}$ Conidia produced on filter paper or leaf surface. 
suspended in $2 \mathrm{ml}$ of sterile distilled water. Droplets of each conidial suspension were placed on the underside of a single detached, immature leaf of Minneola tangelo. Leaves were incubated in a plastic chamber at near $100 \% \mathrm{RH}$ at room temperature $\left(22\right.$ to $\left.24^{\circ} \mathrm{C}\right)$ for $72 \mathrm{~h}$ and evaluated for symptoms of Alternaria brown spot.

\section{RESULTS}

Conditions for sporulation on infected leaves. After soaking infected leaves prior to placement in a humid chamber, 43 to $80 \%$ of the lesions produced mycelial growth, whereas only 17 to $23 \%$ produced conidia (Table 2). Sporulation was greatest when infected leaves were moistened or placed directly into humid chambers. Little mycelial growth or sporulation occurred when leaves were maintained under ambient RH in the laboratory.

Conidial release. No differences were noted between release patterns of conidia produced on filter paper (experiments AA1 to AA6) and those produced on leaf lesions (experiments AA7 to AA10) in their response to environmental factors. Sharp drops in $\mathrm{RH}$ from 90 to $15 \%$ triggered release of large numbers of conidia (Fig. 1). The average number of conidia released during 10-min periods following the sharp changes in RH was 2,260 and was

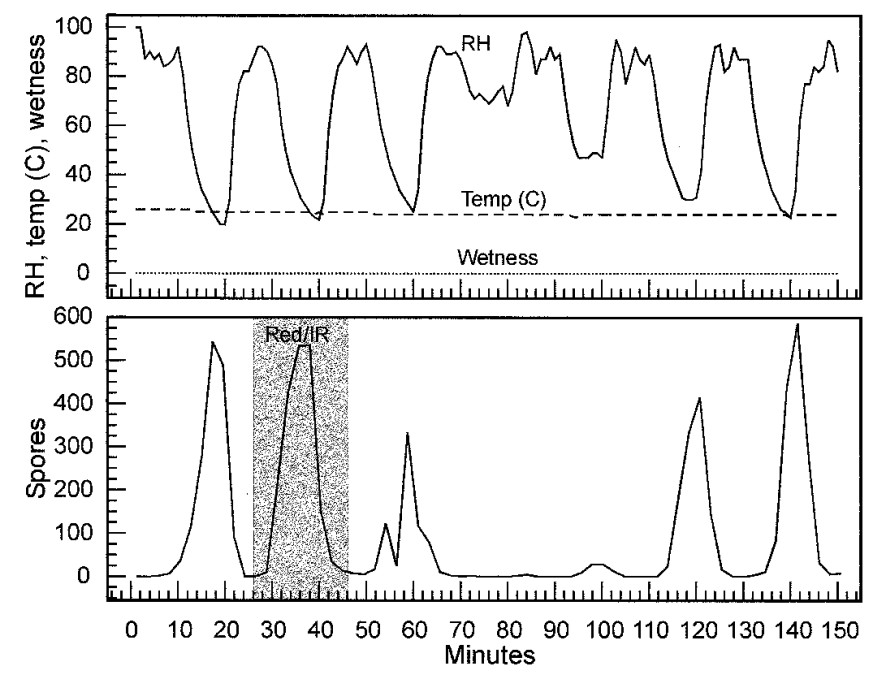

Fig. 1. Conidial release of Alternaria alternata in the computer-controlled environmental chamber in response to changes in relative humidity and to red/infrared irradiation. Conidia produced in vitro on filter paper.

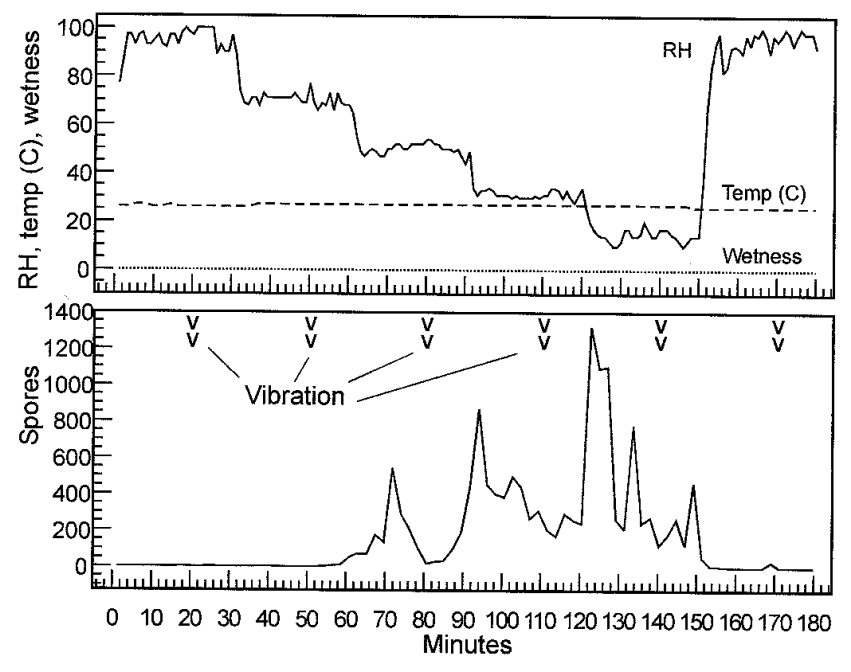

Fig. 2. Conidial release of Alternaria alternata in the computer-controlled environmental chamber in response to changes in relative humidity and to vibration. Conidia produced in vitro on filter paper. significantly greater than the average of 67 released when RH was maintained at $90 \%(t=-3.68, P=0.008)$. Conidial release ceased immediately when $\mathrm{RH}$ returned to $90 \%$. Stepwise reduction of $\mathrm{RH}$ in 20-percentage point increments did not trigger release of conidia until $\mathrm{RH}$ reached $50 \%$, and maximal spore release occurred when $\mathrm{RH}$ was reduced from 30 to $15 \%$ (Fig. 2). A more gradual reduction in RH triggered release of low numbers of conidia (Fig. 3; experiment AA3, data not shown). A sudden increase in $\mathrm{RH}$ from 15 to $90 \%$ also appeared to stimulate release of some conidia. In one experiment using conidia produced on leaf tissue, small numbers of conidia were released constantly while RH was maintained at $50 \%$ (Fig. 4). A reduction of RH to $15 \%$ stimulated additional release of conidia. In another experiment, reducing $\mathrm{RH}$ to $30 \%$ after $1 \mathrm{~h}$ at $50 \%$ did not trigger release of additional conidia (data not shown).

Simulated rainfall events triggered large conidial releases (Figs. 3 and 4). The average number of conidia captured during 10-min periods immediately after rainfall events was 487 and was significantly different from the average of 36 captured during similar periods without rain $(t=-3.56, P=0.016)$. In another experiment, conidia produced on leaf tissue were exposed to 60 -s rain events at half-hour intervals. The first three events produced peaks of more than 250 conidia per $2.4 \mathrm{~min}$, whereas peaks were less than 75 conidia per $2.4 \mathrm{~min}$ following each of the last three events (data not shown).

In experiments using conidia produced on filter paper or on leaf lesions, R/IR irradiation had no effect on conidial release (Figs. 1 and 4 ). The average number of conidia released during and immediately after irradiation was 234 per 10 -min period and was not significantly different from similar periods without irradiation in which 296 per 10 -min period were captured $(t=1.3, P=0.25)$. The pattern of conidial release brought about by changes in $\mathrm{RH}$ was the same whether the conidia were being exposed to $R / I R$ irradiation or not (Fig. 1).

Use of vibration to simulate wind movement of leaves had minor effects on spore release (Figs. 2 and 4). The average number of conidia captured during 10-min periods following a vibration event was 70 and was significantly greater than the average of 29 conidia captured during similar periods without vibration $(t=-2.92, P=0.034)$.

Field studies. Small numbers of conidia were captured yearround, but substantial peaks were observed periodically during the

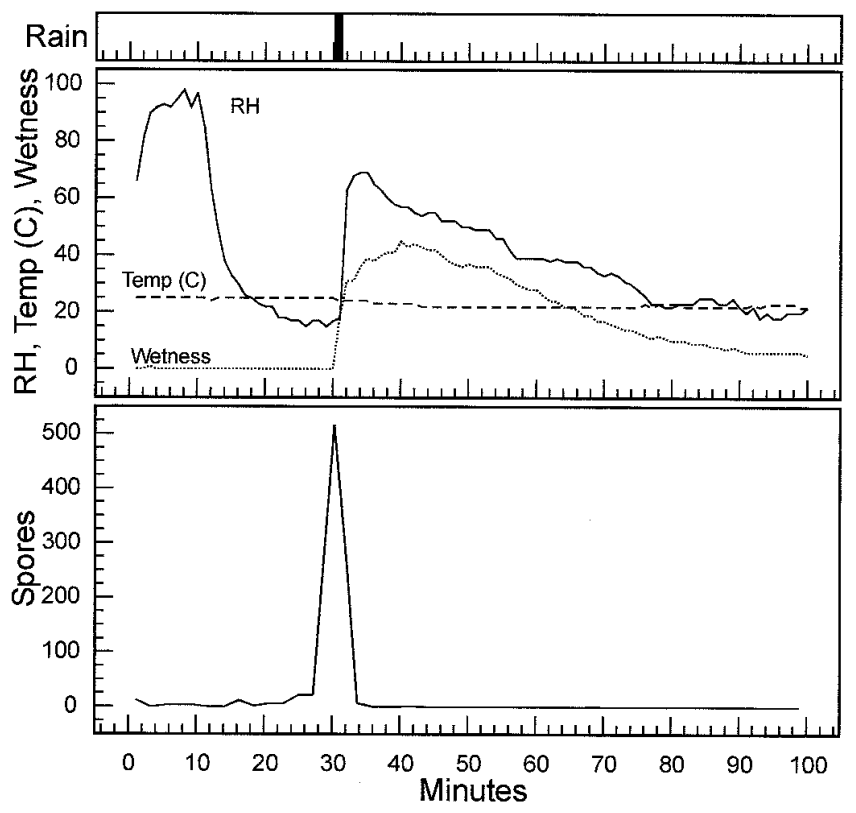

Fig. 3. Conidial release of Alternaria alternata in the computer-controlled environmental chamber in response to a rainfall event. Conidia produced in vitro on filter paper. 
2-year study (Fig. 5). There was no obvious association of the number of conidia trapped with environmental factors. Regression analysis of weekly totals of captured conidia and rainfall amounts was not significant $\left(R^{2}=0.01, P=0.18\right)$. The average number of conidia trapped on days with rain was 36 , which was not significantly different from the average number, 39 , observed on days with no rain $(t=0.23, P=0.81)$. The average number of conidia captured on days following a rain event was 39 and was not significantly different from the number, 36 , on days with no rain the previous day $(t=-0.21, P=0.83)$. Regression analysis of average daily wind speed and total number of conidia captured per day over the 2-year period indicated a significant, but extremely small, effect $\left(R^{2}=0.007, P=0.03\right)$. However, the proportion of hours with leaf wetness was related to the weekly total number of conidia $\left(R^{2}=0.16, P \leq 0.01\right)$. Log transformation of conidial numbers did not greatly affect the outcome of the regression analyses.

Occasionally, peaks in disease incidence on trap plants corresponded to peaks in conidia trapped in 1995 to 1996 , but high levels of infection occurred at some times when conidial numbers were low (Fig. 5). Overall, the disease incidence on trap plants was not significantly related to total weekly rainfall $\left(R^{2}=0.03, P=\right.$ $0.15)$ or to the weekly total number of conidia captured $\left(R^{2}=0.02\right.$, $P=0.67)$. However, there was a relationship between the amount of infection and the proportion of hours with leaf wetness $\left(R^{2}=\right.$ $0.09, P=0.02)$.

A total of 232 colonies of Alternaria spp. grew on the plates of a selective medium exposed in the grove. Conidia from all except one of these colonies produced typical brown spot lesions when transferred to detached immature Minneola tangelo leaves. Thus, nearly all of the conidia captured on spore trap tapes were probably those of the pathogen rather than saprophytes or pathogens of other hosts.

\section{DISCUSSION}

Abundant conidia were produced within $24 \mathrm{~h}$ following wetting of mature Minneola tangelo leaves with Alternaria brown spot lesions. Our field observations indicated that sporulation occurred on mature leaves with lesions on the grove floor as well as those remaining in the canopy the day after a rain event. No sporulation

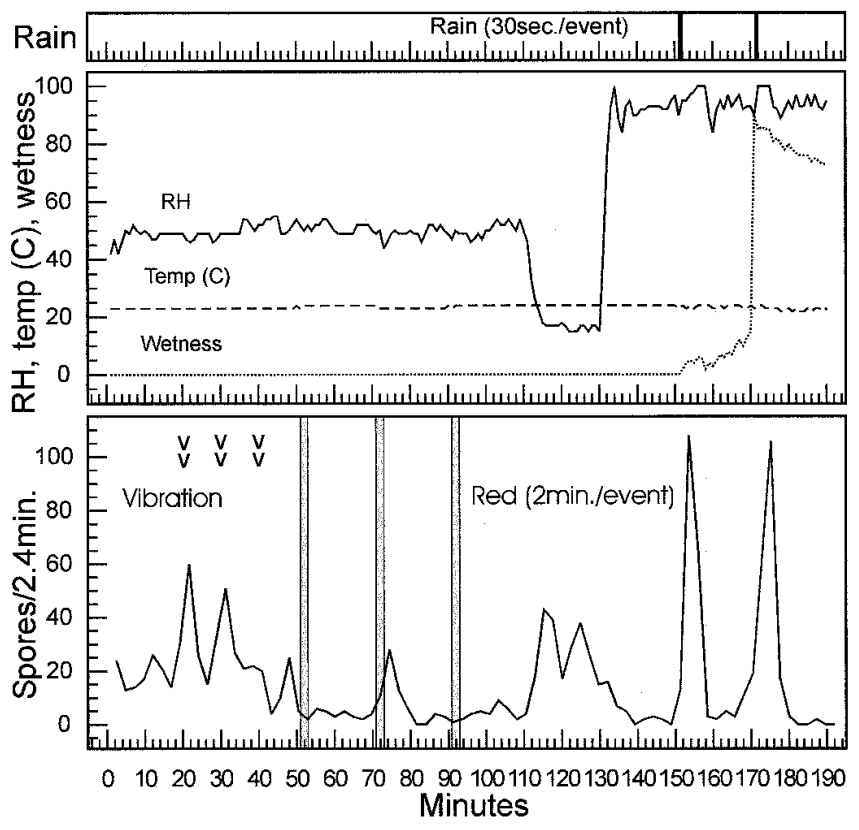

Fig. 4. Conidial release of Alternaria alternata in the computer-controlled environmental chamber in response to vibration, red/infrared irradiation, rainfall events, and changes in relative humidity. Conidia produced on infected leaves of Minneola tangelo. has been observed on necrotic young tissue that had apparently been killed by the Alternaria-associated toxin. Likewise, Pegg (9) was unable to isolate the pathogen from surface-sterilized lesions $24 \mathrm{~h}$ after inoculation. Sporulation was observed only in lesion areas and not in surrounding tissues killed by the toxin. Thus, it appears that leaves and lesions must mature to a certain degree before sporulation occurs. Although minimum conditions for sporulation were not investigated in this study, a light rain or heavy dew should be sufficient to induce sporulation once leaves and lesions are sufficiently mature. As with other Alternaria spp., shorter or interrupted periods of wetness may be sufficient for production of at least some conidia $(11,15)$.

The primary factors stimulating release of conidia were abrupt changes in RH or rainfall events. Vibration appeared to have relatively minor effects, and exposure to R/IR irradiation did not induce conidial release. Release of conidia produced on filter papers followed the same pattern as those produced on leaves; thus, the filter papers serve as a good model system for conidial release studies. The Alternaria brown spot pathogen seems to respond similarly to A. tenuis from banana (8) and A. solani from tomato (4), but did not respond to $\mathrm{R} / \mathrm{IR}$ irradiation or vibration as do many others of the class Hyphomycetes (7). Thus, we were able to clearly define the conditions for conidial production and release in the laboratory. Relating those factors to the number of conidia trapped under field conditions proved more difficult. There was a weak, but significant, relationship between the duration of leaf wetness and the number of conidia that is probably related to conditions needed for spore production. There appeared to be no direct relationship between rainfall events and the number of conidia captured on the spore trap. RH is generally high in Florida, and sudden decreases occur only with the passage of cold fronts in winter and spring. The release of conidia in Florida should be stimulated most commonly by rainfall events. However, in Israel, rapid changes in $\mathrm{RH}$ occur when dew dries, and sharp decreases in RH may play a more significant role in semi-arid areas. Wind movement of leaves may also result in some release of conidia, especially during daylight hours when RH is low, but daily average wind speed was not closely related to conidia captured in this study. With other Alternaria spp., rainfall is most commonly associated with rapid increases in disease development and progress (15). However, the incidence of airborne conidia is often more closely associated with $\mathrm{RH}$, periods of leaf wetness, and wind velocity.

In most annual crops and deciduous fruit trees, the numbers of conidia captured tend to increase as the season progresses (10). Some inoculum is available throughout the year with evergreen trees such as citrus; and in our study, some conidia were trapped virtually every week during a 2-year period. However, in contrast to other crops in which the amount of susceptible tissue increases as the season progresses, susceptible tissue on citrus occurs as four to six sporadic growth flushes per year. In Florida, a strong growth

TABLE 2. Effect of moisture treatments on production of mycelium and conidiophores and the number of conidiophore groups produced on lesions on mature leaves of Minneola tangelo

\begin{tabular}{|c|c|c|c|c|c|c|}
\hline \multirow[b]{2}{*}{ Treatment $^{\mathrm{W}}$} & \multicolumn{2}{|c|}{$\begin{array}{l}\text { Mycelial growth } \\
\qquad(\%)^{\mathrm{x}}\end{array}$} & \multicolumn{2}{|c|}{$\begin{array}{c}\text { Conidiophore } \\
\text { production }(\%)^{\mathrm{x}}\end{array}$} & \multicolumn{2}{|c|}{$\begin{array}{l}\text { Conidiophore } \\
\text { groups/lesion }\end{array}$} \\
\hline & Exp. 1 & Exp. 2 & Exp. 1 & Exp. 2 & Exp. 1 & Exp. 2 \\
\hline Soaked & $80 a^{z}$ & $43 \mathrm{a}$ & $17 \mathrm{~b}$ & $23 \mathrm{bc}$ & $2.3 \mathrm{~b}$ & $6.6 \mathrm{~b}$ \\
\hline Moist & $20 \mathrm{~b}$ & $20 \mathrm{ab}$ & $60 \mathrm{a}$ & $50 \mathrm{a}$ & $18.8 \mathrm{a}$ & $36.7 \mathrm{a}$ \\
\hline High RH & $17 \mathrm{~b}$ & $30 \mathrm{ab}$ & $57 \mathrm{a}$ & $40 a b$ & $11.8 \mathrm{a}$ & $10.7 \mathrm{~b}$ \\
\hline Moderate RH & $0 \mathrm{~b}$ & $0 \mathrm{~b}$ & $10 \mathrm{~b}$ & $0 \mathrm{c}$ & $0.3 \mathrm{~b}$ & $0.0 \mathrm{~b}$ \\
\hline
\end{tabular}

${ }^{\mathrm{w}}$ Soaked $=$ soaked $2 \mathrm{~h}$ and incubated an additional $22 \mathrm{~h}$ at $100 \%$ relative humidity $(\mathrm{RH})$; moist $=$ moistened briefly and incubated $24 \mathrm{~h}$ at $100 \% \mathrm{RH}$; high $\mathrm{RH}=$ incubated at $100 \% \mathrm{RH}$; and moderate $\mathrm{RH}=$ incubated at 50 to $70 \% \mathrm{RH}$.

${ }^{x}$ Percentage of 10 lesions each in three replications.

y Average number per lesion on three replicate groups of 10 lesions each.

${ }^{\mathrm{z}}$ Mean separation by the Waller-Duncan $k$-ratio $t$ test, $P \leq 0.05$. 
flush occurs in the spring (late February to March) followed by periodic flushes of growth throughout the summer and fall. In most areas, susceptible tissue is absent only from mid-November to midFebruary. The observed peaks in conidia probably resulted from growth flushes that became heavily infected and produced abundant conidia. Other flushes may have occurred when conditions were unfavorable for infection and resulted in lower conidial production. We have expanded our field observations to include assess-

\section{4-1995}
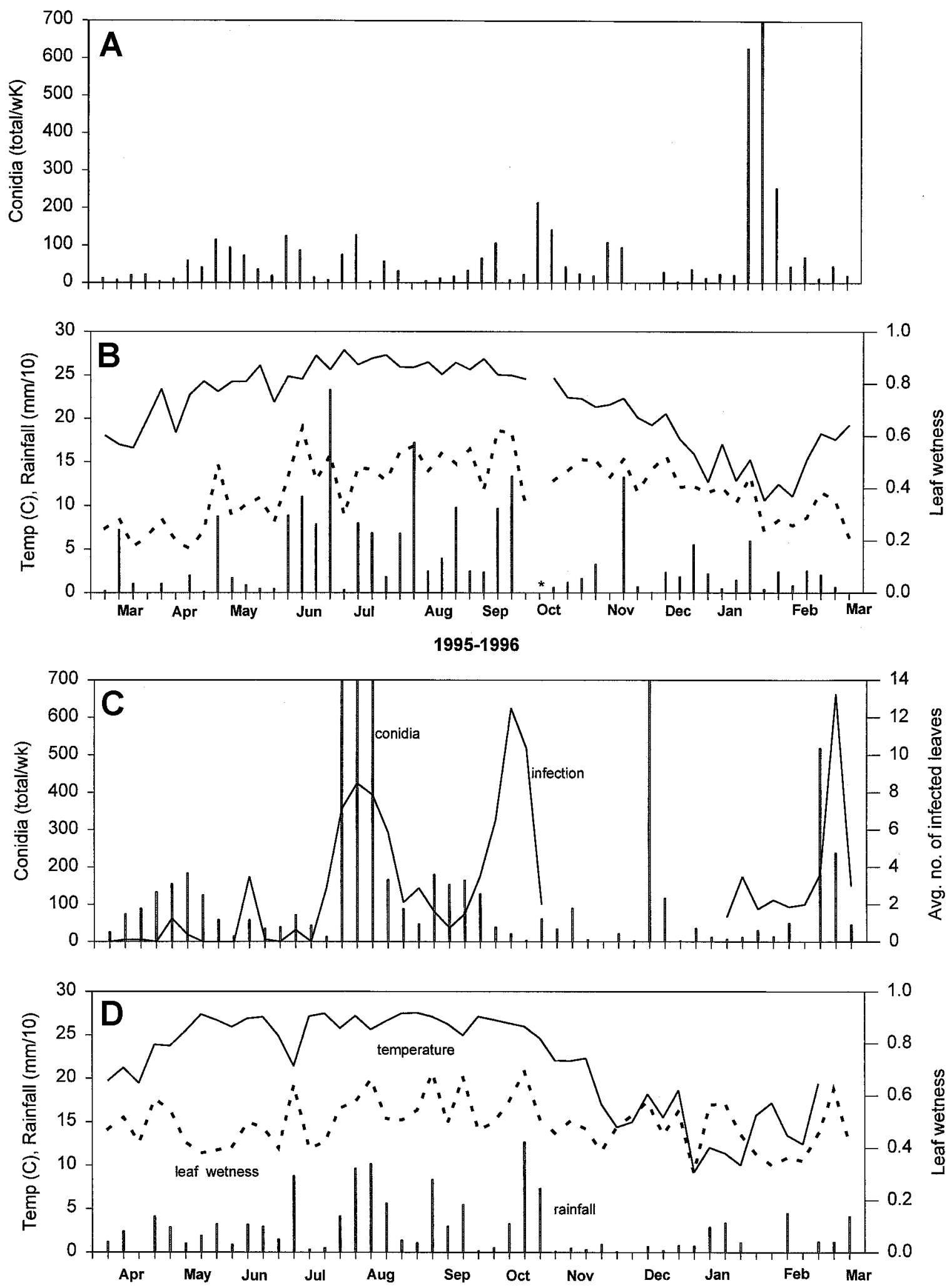

Fig. 5. Number of conidia of Alternaria alternata, average weekly temperature, proportion of hours with leaf wetness, and infection of Dancy tangerine trap plants in a Minneola tangelo grove near Polk City, FL. A and C, Total conidial numbers recorded per week using a 7-day recording volumetric spore trap (vertical bars); B and D, average weekly temperature (solid lines); and B and D, proportion of hours weekly with leaf wetness (dashed lines) from 1994 to 1996. C, Infection data for 1995 to 1996 represents the average number of infected leaves per plant on eight Dancy tangerine seedlings placed in the grove for 1 week (solid line). Missing data are indicated by gaps in the line graphs or asterisks in the bar graphs. Values for conidial numbers that surpassed the maxima in the graph were 1,386 for 1994 to 1995 and 7,128, 86, 8,580, and 1,148 in chronological order for 1995 to 1996. 
ments of the amount of susceptible tissue in order to determine its role in the occurrence of peaks of conidia captured.

In many cases, it is difficult to relate conidial numbers to disease development, because large numbers of conidia of saprophytic species or pathogens of weeds are also trapped $(10,14)$. In citrus groves, this does not appear to be the case, since nearly all of the isolates $(99.6 \%)$ collected on plates of selective media were pathogenic to Minneola tangelo. This probably accounts for the high levels of infection sometimes observed when conidial populations appeared to be low.

The importance of large numbers of conidia for significant infection may be questioned, however, since we observed considerable infection of trap plants even when conidial numbers were low. In future experiments, we will emphasize the availability of susceptible tissue as well as environmental factors on the epidemiology of the pathogen in the field. The period over which infection and environmental factors are measured may also be important, and it may be necessary to make determinations over shorter intervals. Symptoms can develop in 36 to $48 \mathrm{~h}$ after infection and, thus, the weekly intervals used for determination of disease severity in this study were probably too long to relate severity to environmental factors and inoculum availability. The optimum temperature and the duration of leaf wetness necessary for infection are not known for this pathosystem and will be the subject of future investigation.

\section{ACKNOWLEDGMENTS}

Florida Agricultural Experiment Station Journal Series No. R-05942.

\section{LITERATURE CITED}

1. Canihos, Y., Erkilic, A., and Timmer, L. W. 1997. First report of Alternaria brown spot of Minneola tangelo in Turkey. Plant Dis. 81:1214.

2. Castro, B. L., Leguizamon, J. E., and Lopez, J. A. 1994. La mancha foliar de los citricos en la zona cafetera. Avances Técnicos No. 198. Cenicafe, Chinchiná, Caldas, Colombia.
3. Gadoury, D. M., and MacHardy, W. E. 1983. A 7-day recording volumetric spore trap. Phytopathology 73:1526-1531.

4. Gottwald, T. R., Trocine, T. M., and Timmer, L. W. 1997. A computercontrolled environmental chamber for the study of aerial fungal spore release. Phytopathology 87:1078-1084.

5. Kiely, T. B. 1964. Brown spot of Emperor mandarin. Agric. Gaz. N.S.W. 75:854-856.

6. Kohmoto, K., Scheffer, R. P., and Whiteside, J. O. 1979. Host-selective toxins from Alternaria citri. Phytopathology 69:667-671.

7. Leach, C. M. 1975. Influence of relative humidity and red-infrared radiation on violent spore release by Drechslera turcica and other fungi. Phytopathology 65:1303-1312.

8. Meredith, D. S. 1963 . Violent spore release in some fungi imperfecti. Ann. Bot. (Lond.) N. S. 27:39-47.

9. Pegg, K. G. 1966. Studies of a strain of Alternaria citri Pierce, the causal organism of brown spot of Emperor mandarin. Queensl. J. Agric. Anim. Sci. 23:14-18.

10. Pryor, B. M., Davis, R. M., and Gilbertson, R. L. 1994. Detection and eradication of Alternaria radicina on carrot seed. Plant Dis. 78:452-456.

11. Rotem, J. 1994. The Genus Alternaria. Biology, Epidemiology, and Pathogenicity. The American Phytopathological Society, St. Paul, MN.

12. Schutte, G. C., Lesar, K. H., Pelser, P. du T., and Swart, S. H. 1992. The use of tebuconazole for the control of Alternaria alternata on 'Minneola' tangelos and its potential to control post-harvest decay when applied as a pre-harvest spray. Proc. Int. Soc. Citricult. 7:1070-1074.

13. Solel, Z. 1991. Alternaria brown spot on Minneola tangelos in Israel. Plant Pathol. 40:145-147.

14. Solel, Z., Gottwald, T. R., Ibañez, A. M., and Timmer, L. W. 1996. Conidial release and field population of Alternaria alternata pv. citri, the cause of brown spot of citrus. (Abstr.) Phytopathology (Suppl.) 86:S22.

15. Strandberg, J. O. 1992. Alternaria species that attack vegetable crops: Biology and options for disease management. Pages 175-208 in: Alternaria: Biology, Plant Diseases and Metabolites. J. Chelkowski and A. Visconti, eds. Elsevier Science Publishers, Amsterdam, the Netherlands.

16. Whiteside, J. O. 1976. A newly recorded Alternaria-induced brown spot disease on Dancy tangerines in Florida. Plant Dis. Rep. 60:326-329.

17. Whiteside, J. O. 1979. Alternaria brown spot of Dancy tangerines and its control. Proc. Fla. State Hortic. Soc. 92:34-37.

18. Whiteside, J. O. 1988. Alternaria brown spot of mandarin. Page 8 in: Compendium of Citrus Diseases. J. O. Whiteside, S. M. Garnsey, and L. W. Timmer, eds. The American Phytopathological Society, St. Paul, MN. 